Received: 2016.11 .24

Accepted: 2016.12 .25

Published: 2017.10.20

\section{Authors' Contribution:}

A Study Design

B Data Collection

C Statistical Analysis

D Data Interpretation

E Manuscript Preparation

F Literature Search

G Funds Collection

\title{
Diffusion-Weighted Imaging in the Oral and Maxillofacial Region: Usefulness of Apparent Diffusion Coefficient Maps and Maximum Intensity Projection for Characterization of Normal Structures and Lesions
}

\author{
Ichiro Ogura ${ }^{\text {ABBCDEF }}$, Yoshihiko Sasaki ${ }^{10 \mathrm{E}}$, Ayako Kameta ${ }^{2 \text { Б्F }}$, Mikiko Sue ${ }^{1 \mathrm{BD}}$, \\ Takaaki Oda ${ }^{1 \mathrm{BF}}$ \\ ${ }^{1}$ Department of Radiology, The Nippon Dental University Niigata Hospital, Niigata, Japan \\ 2 Department of Oral and Maxillofacial Radiology, The Nippon Dental University School of Life Dentistry at Niigata, Niigata, \\ Japan
}

Author's address: Ichiro Ogura, Department of Radiology, The Nippon Dental University Niigata Hospital, 1-8 Hamaura-cho, Chuo-ku, Niigata, Niigata 951-8580, Japan, e-mail: ogura@ngt.ndu.ac.jp

Source of support: This work was supported by NDU Grants N-16020

\section{Summary}

Background: The aim of this study was to investigate diffusion-weighted imaging (DWI) in the oral and maxillofacial region, with a special focus on the usefulness of apparent diffusion coefficient (ADC) maps and maximum intensity projection (MIP) for characterization of normal structures and lesions.

Material/Methods:

Thirty-five patients who underwent magnetic resonance imaging (MRI) for diagnosis of oral and maxillofacial lesions were included in this prospective study. DWI was performed on a $1.5 \mathrm{~T}$ unit, with b factor of 0 and $800 \mathrm{~s} / \mathrm{mm}^{2}$; moreover, ADC maps were generated. ADC values were measured for normal structures, odontogenic infections, squamous cell carcinomas (SCC), and hemangiomas.

Results: $\quad$ As regards the normal structures, the mean ADC value of the cerebrospinal fluid $\left(3.65 \pm 0.60 \times 10^{-3}\right.$ $\left.\mathrm{mm}^{2} / \mathrm{s}\right)$ in the upper neck area was higher than that of the spinal cord $\left(0.74 \pm 0.15 \times 10^{-3} \mathrm{~mm}^{2} / \mathrm{s}\right.$, $\mathrm{P}=0.000)$, lymph nodes $\left(0.87 \pm 0.17 \times 10^{-3} \mathrm{~mm}^{2} / \mathrm{s}, \mathrm{P}=0.000\right)$, and Waldeyer's ring $\left(0.92 \pm 0.29 \times 10^{-3}\right.$ $\left.\mathrm{mm}^{2} / \mathrm{s}, \mathrm{P}=0.000\right)$. The mean ADC value of hemangiomas $\left(1.52 \pm 0.31 \times 10^{-3} \mathrm{~mm}^{2} / \mathrm{s}\right)$ was higher than that of odontogenic infections $\left(0.85 \pm 0.36 \times 10^{-3} \mathrm{~mm}^{2} / \mathrm{s}, \mathrm{P}=0.034\right)$ and SCC $\left(1.38 \pm 0.22 \times 10^{-3} \mathrm{~mm}^{2} / \mathrm{s}\right.$, $\mathrm{P}=0.840$ ). Furthermore, MIP (DWI) showed the normal structures and lesions in the oral and maxillofacial region in an improved way.

Conclusions: DWI, ADC maps, and MIP can be used to characterize and differentiate normal structures and lesions in the oral and maxillofacial region.

MeSH Keywords: $\quad$ Diffusion Magnetic Resonance Imaging • Head and Neck Neoplasms • Magnetic Resonance Imaging

PDF file: $\quad$ http://www.polradiol.com/abstract/index/idArt/902524

\section{Background}

Diagnosis of head and neck lesions is difficult due to the complicated anatomic structure and different histological components of the many tissues of the neck [1]. Imaging of oral and maxillofacial lesions is not only important for diagnosis of lesions, but also for differentiation of benign lesions from malignant lesions and staging of tumors. While conventional imaging methods mainly evaluate morphological properties, their value is limited in recognizing prognostic characteristics such as benign-malignant differentiation of lesions [2]. Routine magnetic resonance imaging (MRI) is a time-consuming method, which is sensitive to differences between examiners and may require the 
use of contrast material. With development of rapid MRI sequences, such as echo-planar (EPI), fast advanced spin echo (FASE), the susceptibility to artifacts that limit the use of MRI for the head and neck region and limitations linked to duration of examinations have been significantly reduced [3].

Diffusion-weighted imaging (DWI) is a short sequence produced from EPI, FASE sequences. DWI with apparent diffusion coefficient (ADC) maps, that provide quantitative indices of water diffusivity for each voxel in the studied tissues, can facilitate data acquisition and processing without the use of ionizing radiation or contrast agents [4]. Therefore, in recent years, DWI has been considered as a promising noninvasive biomarker for predicting and monitoring treatment responses. Furthermore, some studies have assessed the role of DWI with calculation of ADC in the differentiation between benign and malignant head and neck masses [5-8].

However, to the best of our knowledge, DWI in the oral and maxillofacial region, especially with a focus of the usefulness of $\mathrm{ADC}$ maps and maximum intensity projection (MIP) for characterization of lesions, has not been reported in the literature. The aim of this study was to investigate DWI in the oral and maxillofacial region, with a special focus on the usefulness of ADC maps and MIP for characterization of normal structures and lesions.

\section{Material and Methods}

\section{Patients}

This retrospective study was approved by the ethics committee of our institution. After providing written informed consent, 35 patients (16 male, 19 female; age 33-89 years, mean age 59.0 years) with suspected oral and maxillofacial lesions underwent MRI in our university hospital from October 2016 to November 2016. We included 6 patients with odontogenic infections (3 male, 3 female; age 51-79 years, mean age 65.8 years), 4 patients with squamous cell carcinomas (SCC; 3 male, 1 female; age 61-81 years, mean age 69.8 years), and 3 patients with hemangiomas ( 0 male, 3 female; age 62-89 years, mean age 72.7 years). The histopathological diagnoses of those lesions were obtained after surgery in all cases.

\section{Magnetic resonance imaging}

The MR images (1.5 Tesla MR unit with a head coil; EXCELART Vantage MRT-2003; Toshiba Medical Systems, Otawara, Japan;) included unenhanced axial Tl-weighted images [TlWI; repetition time (TR) $660 \mathrm{~ms}$, echo time (TE) $12 \mathrm{~ms}$ ], T2-weighted images (T2WI; TR $4000 \mathrm{~ms}$, TE $120 \mathrm{~ms}$ ), short TI inversion recovery images (STIR; TR $2500 \mathrm{~ms}$, TE $15 \mathrm{~ms}$, TI $190 \mathrm{~ms}$ ), and coronal Tl-weighted images. The DWI sequence was obtained with $b$ values of 0 and $800 \mathrm{~s} / \mathrm{mm}^{2}$, with an EPI technique. The following technical parameters were used: TR $8476 \mathrm{~ms}$, TE $80 \mathrm{~ms}$. The ADC maps and MIP (DWI) were automatically calculated based on the DWI with $\mathrm{b}=800 \mathrm{~s} / \mathrm{mm}^{2}$.

\section{Image evaluation}

Two oral and maxillofacial radiologists, with over 20 years of experience, independently reviewed all images, and discrepancies were resolved by consensus. The MR images of the lesions were assessed with special attention to intensity changes. We used regions of interest (ROI) to calculate the $\mathrm{ADC}$ values on $\mathrm{ADC}$ maps. We placed three ROIs with similar sizes within the lesions to obtain a mean ADC value. We also measured ADC values of normal structures including the Waldeyer's ring, lymph nodes, spinal cord, and cerebrospinal fluid in the upper neck area.

\section{Statistical analysis}

The statistical analysis with respect to the ADC values of the normal structures and lesions in the oral and maxillofacial region was performed with one-way repeated measures analysis of variance. If there was a significant difference, then the Tukey's HSD test for multiple comparisons was performed to determine which pair showed a significant difference. The statistical analysis with respect to MRI features of the oral and maxillofacial lesions was performed with the Pearson's chi-squared test. These analyses were performed with the statistical package IBM SPSS Statistics, version 24 (IBM Japan, Tokyo, Japan). A P value lower than 0.05 was considered as statistically significant.

\section{Results}

Table 1 shows the ADC values of normal structures and lesions in the oral and maxillofacial region. As regards the normal structures, the mean ADC value of the cerebrospinal fluid $\left(3.65 \pm 0.60 \times 10^{-3} \mathrm{~mm}^{2} / \mathrm{s}\right)$ in the upper neck area was higher than that of the spinal cord $\left(0.74 \pm 0.15 \times 10^{-3}\right.$ $\left.\mathrm{mm}^{2} / \mathrm{s}, \mathrm{P}=0.000\right)$, lymph nodes $\left(0.87 \pm 0.17 \times 10^{-3} \mathrm{~mm}^{2} / \mathrm{s}\right.$, $\mathrm{P}=0.000)$, and Waldeyer's ring $\left(0.92 \pm 0.29 \times 10^{-3} \mathrm{~mm}^{2} / \mathrm{s}\right.$, $\mathrm{P}=0.000$ ). Figure 1 shows MRI features of the normal structures in the oral and maxillofacial region. MIP (DWI) showed the normal structures in the oral and maxillofacial region in an improved way (Figure $1 \mathrm{D}-1 \mathrm{~F}$ ). As regards the lesions in the oral and maxillofacial region, the mean $\mathrm{ADC}$ value of hemangiomas $\left(1.52 \pm 0.31 \times 10^{-3} \mathrm{~mm}^{2} / \mathrm{s}\right)$ was higher than that of odontogenic infections $\left(0.85 \pm 0.36 \times 10^{-3} \mathrm{~mm}^{2} / \mathrm{s}\right.$, $\mathrm{P}=0.034)$ and SCC $\left(1.38 \pm 0.22 \times 10^{-3} \mathrm{~mm}^{2} / \mathrm{s}, \mathrm{P}=0.840\right)$.

Table 2 shows the comparison between oral and maxillofacial lesions with respect to MRI features. All cases showed low signal intensity on TlWI and high signal intensity on STIR and DWI. All patients with odontogenic infections showed high signal intensity on T2WI, patients with SCC showed middle signal intensity ( 3 patients) and low signal intensity (1 patient) on T2WI, and patients with hemangiomas showed high signal intensity ( 2 patients) and middle signal intensity ( 1 patient) on T2WI $(\mathrm{P}=0.032)$. All patients with odontogenic infections and all patients with SCC showed low signal intensity on ADC maps, and patients with hemangiomas showed middle signal intensity (2 patients) and low signal intensity (1 patient) on ADC maps $(\mathrm{P}=0.019)$. Figures $2-4$ show MRI features of odontogenic infections, SCC, and hemangiomas, respectively. MIP (DWI) showed the lesions in the oral and maxillofacial region in an improved way. 
Table 1. ADC values of normal structures and lesions in the oral and maxillofacial region.

\begin{tabular}{|c|c|c|c|c|}
\hline & \multirow{2}{*}{ Number } & \multicolumn{2}{|c|}{$A D C\left(\times 10^{-3} \mathrm{~mm}^{2} \mathrm{~s}^{-1}\right)$} & \multirow{2}{*}{$P$ value } \\
\hline & & Mean \pm SD & (Range) & \\
\hline \multicolumn{5}{|c|}{ Normal structures in the upper neck area } \\
\hline Spinal cord & 35 & $0.74 \pm 0.15$ & $(0.46-0.99)$ & 0.000 \\
\hline Lymph node & 35 & $0.87 \pm 0.17$ & $(0.55-1.19)$ & 0.000 \\
\hline Waldeyer's ring & 35 & $0.92 \pm 0.29$ & $(0.54-1.52)$ & 0.000 \\
\hline Cerebrospinal fluid & 35 & $3.65 \pm 0.60$ & $(2.76-4.72)$ & - \\
\hline \multicolumn{5}{|c|}{ Lesions in the oral and maxillofacial region } \\
\hline Odontogenic infection & 6 & $0.85 \pm 0.36$ & $(0.43-1.31)$ & 0.034 \\
\hline Squamous cell carcinoma & 4 & $1.38 \pm 0.22$ & $(1.20-1.70)$ & 0.840 \\
\hline Hemangioma & 3 & $1.52 \pm 0.31$ & $(1.16-1.71)$ & - \\
\hline
\end{tabular}

ADC - apparent diffusion coefficient; SD - standard deviation.

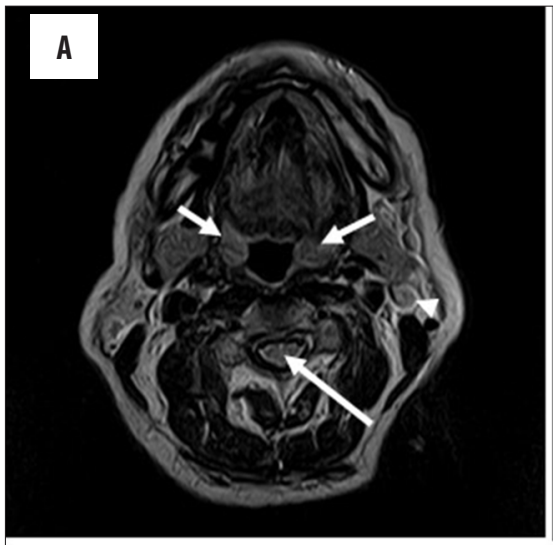

D

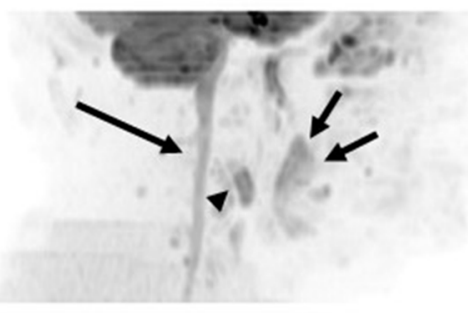

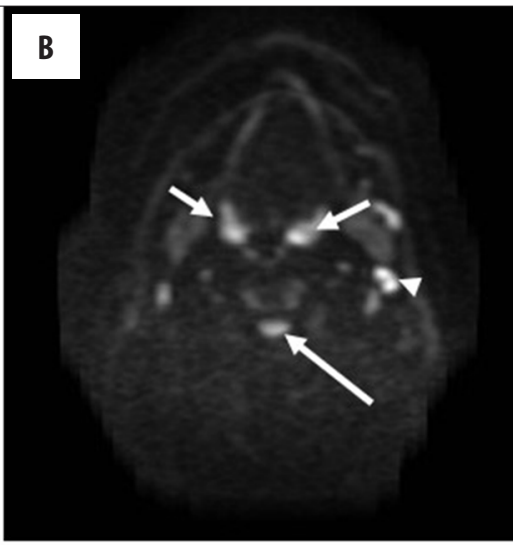

$\mathbf{E}$

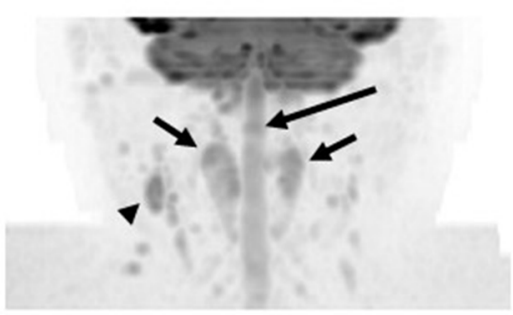

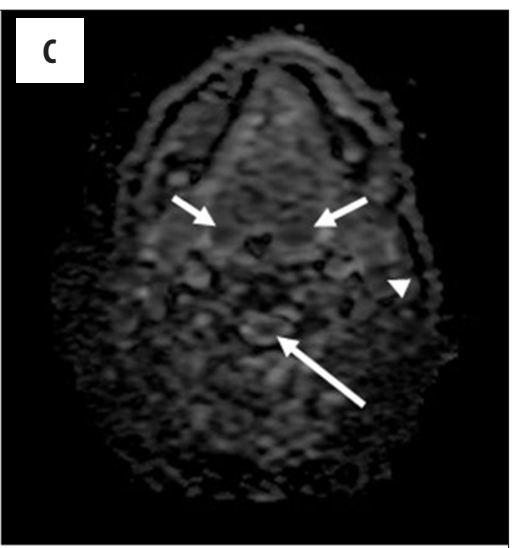

$\mathbf{F}$

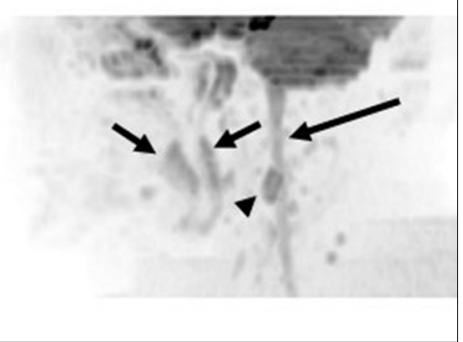

Figure 1. Normal structures in a 64-year-old male. T2-weighted image shows the spinal cord (long arrow), Waldeyer's ring (short arrows), and lymph node (arrowhead) (A). Diffusion-weighted image shows the spinal cord (long arrow), Waldeyer's ring (short arrows), and lymph node (arrowhead) (B). Apparent diffusion coefficient map shows the spinal cord (long arrow), Waldeyer's ring (short arrows), and lymph node (arrowhead) (C). Maximum intensity projection (diffusion-weighted image) shows the spinal cord (long arrow), Waldeyer's ring (short arrows), and lymph node (arrowhead) (D-F).

\section{Discussion}

There are very few studies in the literature that have investigated the role of DWI in evaluating oral and maxillofacial lesions $[6,9]$. Therefore, this study aimed to examine DWI in the oral and maxillofacial region, with a special focus on the usefulness of ADC maps and MIP for characterization of normal structures and lesions.
Helenius et al. [10] showed that ADC values in the normal human brain were the highest in the cortical gray matter $\left(0.89 \pm 0.04 \times 10^{-3} \mathrm{~mm}^{2} / \mathrm{s}\right)$, lower in the deep gray matter $\left(0.75 \pm 0.03 \times 10^{-3} \mathrm{~mm}^{2} / \mathrm{s}\right)$, and the lowest in the white matter $\left(0.70 \pm 0.03 \times 10^{-3} \mathrm{~mm}^{2} / \mathrm{s}\right)$. In this study, as regards the normal structures in 35 patients, the mean ADC value of the cerebrospinal fluid $\left(3.65 \pm 0.60 \times 10^{-3} \mathrm{~mm}^{2} / \mathrm{s}\right)$ in the upper neck area was higher than that of the spinal cord $\left(0.74 \pm 0.15 \times 10^{-3} \mathrm{~mm}^{2} / \mathrm{s}, \mathrm{P}=0.000\right)$, lymph nodes 
Table 2. Comparison among oral and maxillofacial lesions in MRI features.

\begin{tabular}{|c|c|c|c|c|c|c|c|}
\hline T1-weighted image & \multicolumn{2}{|c|}{$\begin{array}{c}\text { Odontogenic MRI } \\
\text { sequence infection (6) }\end{array}$} & \multicolumn{2}{|c|}{$\begin{array}{l}\text { Squamous cell } \\
\text { carcinoma (4) }\end{array}$} & \multicolumn{2}{|c|}{$\begin{array}{l}\text { Hemangioma } \\
\text { (3) }\end{array}$} & $P$ value \\
\hline Low signal intensity & 6 & $(100 \%)$ & 4 & $(100 \%)$ & 3 & $(100 \%)$ & \\
\hline T2-weighted image & & & & & & & 0.032 \\
\hline High signal intensity & 6 & $(100 \%)$ & 0 & $(0 \%)$ & 2 & $(66.7 \%)$ & \\
\hline Middle signal intensity & 0 & $(0 \%)$ & 3 & $(75.0 \%)$ & 1 & $(33.3 \%)$ & \\
\hline Low signal intensity & 0 & $(0 \%)$ & 1 & $(25.0 \%)$ & 0 & $(0 \%)$ & \\
\hline \multicolumn{8}{|l|}{ Short TI inversion recovery } \\
\hline High signal intensity & 6 & $(100 \%)$ & 4 & $(100 \%)$ & 3 & $(100 \%)$ & \\
\hline \multicolumn{8}{|l|}{ Diffusion-weighted image } \\
\hline High signal intensity & 6 & $(100 \%)$ & 4 & $(100 \%)$ & 3 & $(100 \%)$ & \\
\hline Apparent diffusion coefficient map & & & & & & & 0.019 \\
\hline Middle signal intensity & 0 & $(0 \%)$ & 0 & $(0 \%)$ & 2 & $(66.7 \%)$ & \\
\hline Low signal intensity & 6 & $(100 \%)$ & 4 & $(100 \%)$ & 1 & (33.3\%) & \\
\hline
\end{tabular}
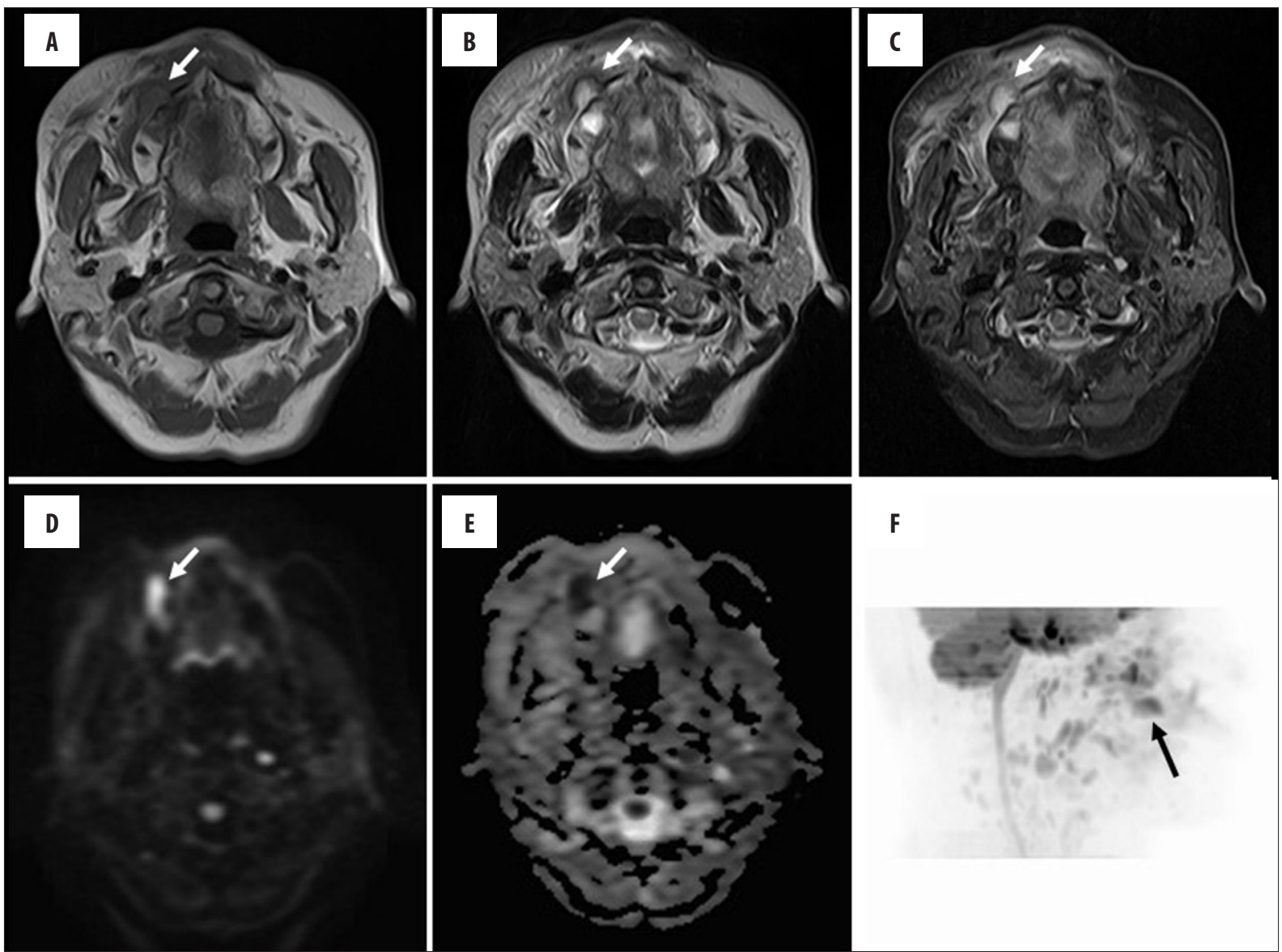

$\mathbf{F}$

Figure 2. 0dontogenic infection of the right side of the buccal region in a 64-year-old female. T1-weighted image shows a low-signal intensity area (arrow) (A). T2-weighted image shows a high-signal intensity area (arrow) (B). Short TI inversion recovery image shows a high-signal intensity area (arrow) (C). Diffusion-weighted image shows a high-signal intensity area (arrow) (D). Apparent diffusion coefficient map shows a lowsignal intensity area (arrow) (E). Maximum intensity projection (diffusion-weighted image) shows lesions in an improved way (arrow) (F). 

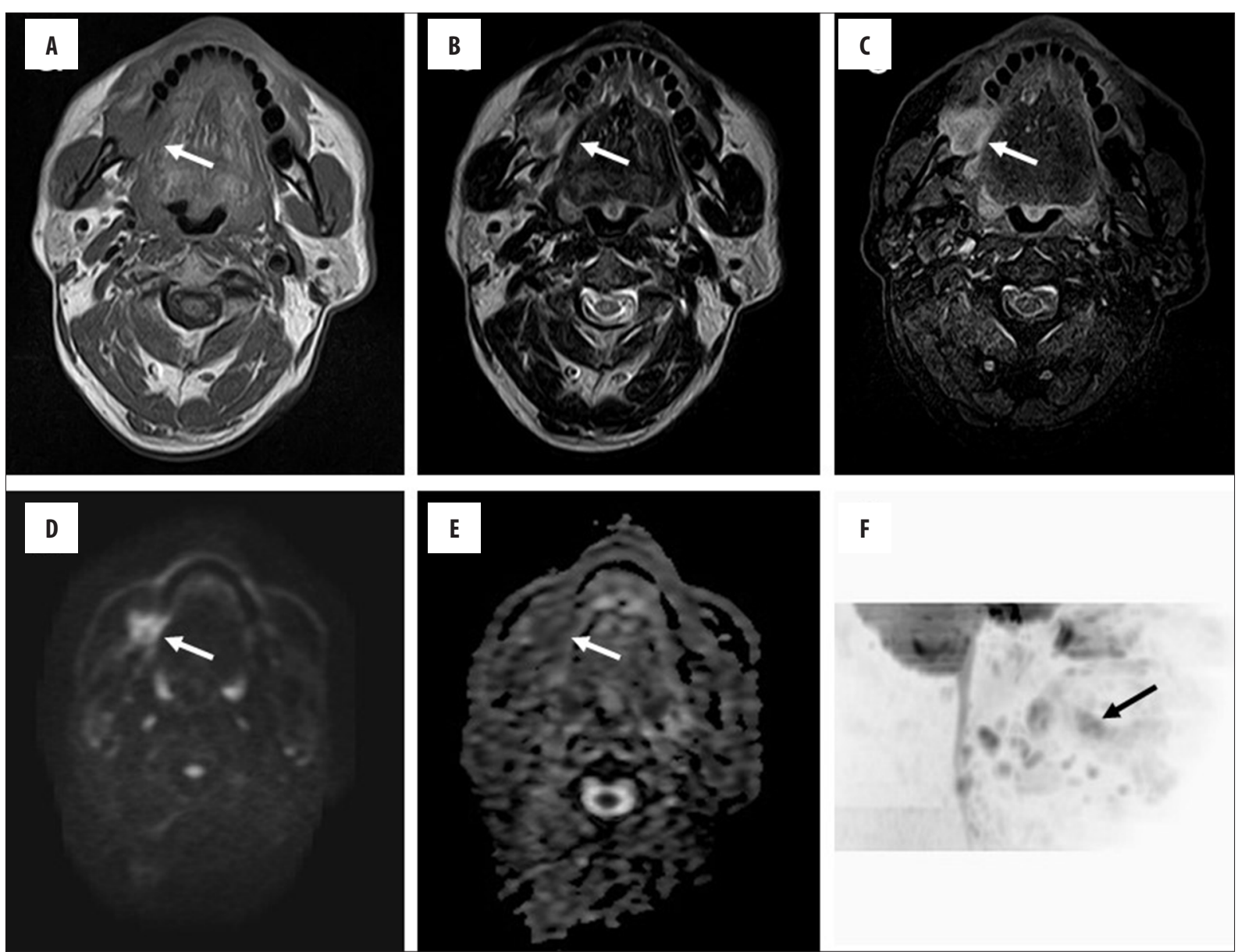

Figure 3. Squamous cell carcinoma of the right side of the mandible in a 61-year-old male. T1-weighted image shows a low-signal intensity area (arrow) (A). T2-weighted image shows a middle-signal intensity area (arrow) (B). Short TI inversion recovery image shows a high-signal intensity area (arrow) (C). Diffusion-weighted image shows a high-signal intensity area (arrow) (D). Apparent diffusion coefficient map shows a low-signal intensity area (arrow) (E). Maximum intensity projection (diffusion-weighted image) shows lesions in an improved way (arrow) (F).

$\left(0.87 \pm 0.17 \times 10^{-3} \mathrm{~mm}^{2} / \mathrm{s}, \mathrm{P}=0.000\right)$, and Waldeyer's ring $\left(0.92 \pm 0.29 \times 10^{-3} \mathrm{~mm}^{2} / \mathrm{s}, \mathrm{P}=0.000\right)$. Furthermore, MIP (DWI) showed the normal structures in the oral and maxillofacial region in an improved way. We consider that the evaluation of $\mathrm{ADC}$ values in the normal structures is important for differential diagnosis of oral and maxillofacial lesions.

Kito et al. [9] studied neck abscess of the oral and maxillofacial region and found that the ADC values of abscesses and inflammatory areas were significantly lower than the ADC values of normal tissues. Guo et al. [11] reported that the combination of high signal on DWI and reduced ADC values within abscesses was characteristic for cerebral abscesses and differentiated abscesses from cystic or necrotic neoplasms. In this study, all cases with odontogenic infections showed low signal intensity on TlWI and ADC maps, and high signal intensity on STIR and DWI. Furthermore, all patients with odontogenic infections showed high signal intensity on T2WI. We consider that the protein complexes in the necrotic parts of the inflammatory lesions and possible presence of microorganisms with inflammatory cells limit the diffusion of water molecules, which leads to low ADC values.
The ADC values of malignant lesions have been found to be significantly lower than those of benign lesions in the head and neck region [2]. Serifoglu et al. [1] indicated that the median $\mathrm{ADC}$ value of malignant tumors and benign lesions were $0.72 \times 10^{-3} \mathrm{~mm}^{2} / \mathrm{s}$ and $1.17 \times 10^{-3} \mathrm{~mm}^{2} / \mathrm{s}$, respectively $(\mathrm{P}<0.001)$. Sakamoto et al. [6] showed that the mean ADC value of cysts was $2.41 \pm 0.48 \times 10^{-3} \mathrm{~mm}^{2} / \mathrm{s}$, which was significantly higher than that of benign $\left(1.48 \pm 0.62 \times 10^{-3}\right.$ $\left.\mathrm{mm}^{2} / \mathrm{s}\right)$ and malignant $\left(1.23 \pm 0.45 \times 10^{-3} \mathrm{~mm}^{2} / \mathrm{s}\right)$ tumors $(\mathrm{P}<0.001)$. Srinivasan et al. [12] showed that there was a statistically significant difference $(\mathrm{P}=0.004)$ between the mean ADC values in the benign $\left(1.505 \pm 0.487 \times 10^{-3}\right.$ $\left.\mathrm{mm}^{2} / \mathrm{s}\right)$ and malignant $\left(1.071 \pm 0.293 \times 10^{-3} \mathrm{~mm}^{2} / \mathrm{s}\right)$ lesions in the head and neck. Abdel Razek et al. [13] showed that the mean ADC values of malignant tumors, benign solid masses, and cystic lesions were $0.93 \pm 0.18 \times 10^{-3} \mathrm{~mm}^{2} / \mathrm{s}$, $1.57 \pm 0.26 \times 10^{-3} \mathrm{~mm}^{2} / \mathrm{s}$, and $2.01 \pm 0.21 \times 10^{-3} \mathrm{~mm}^{2} / \mathrm{s}$, respectively. Furthermore, Maeda et al. [14] showed that the mean ADC values were $0.96 \pm 0.11 \times 10^{-3} \mathrm{~mm}^{2} / \mathrm{s}$ for SCC and $0.65 \pm 0.09 \times 10^{-3} \mathrm{~mm}^{2} / \mathrm{s}$ for lymphomas in the head and neck; this difference was significant $(\mathrm{P}<0.001)$. In this study, as regards the lesions in the oral and maxillofacial region, the mean $\mathrm{ADC}$ value of hemangiomas 

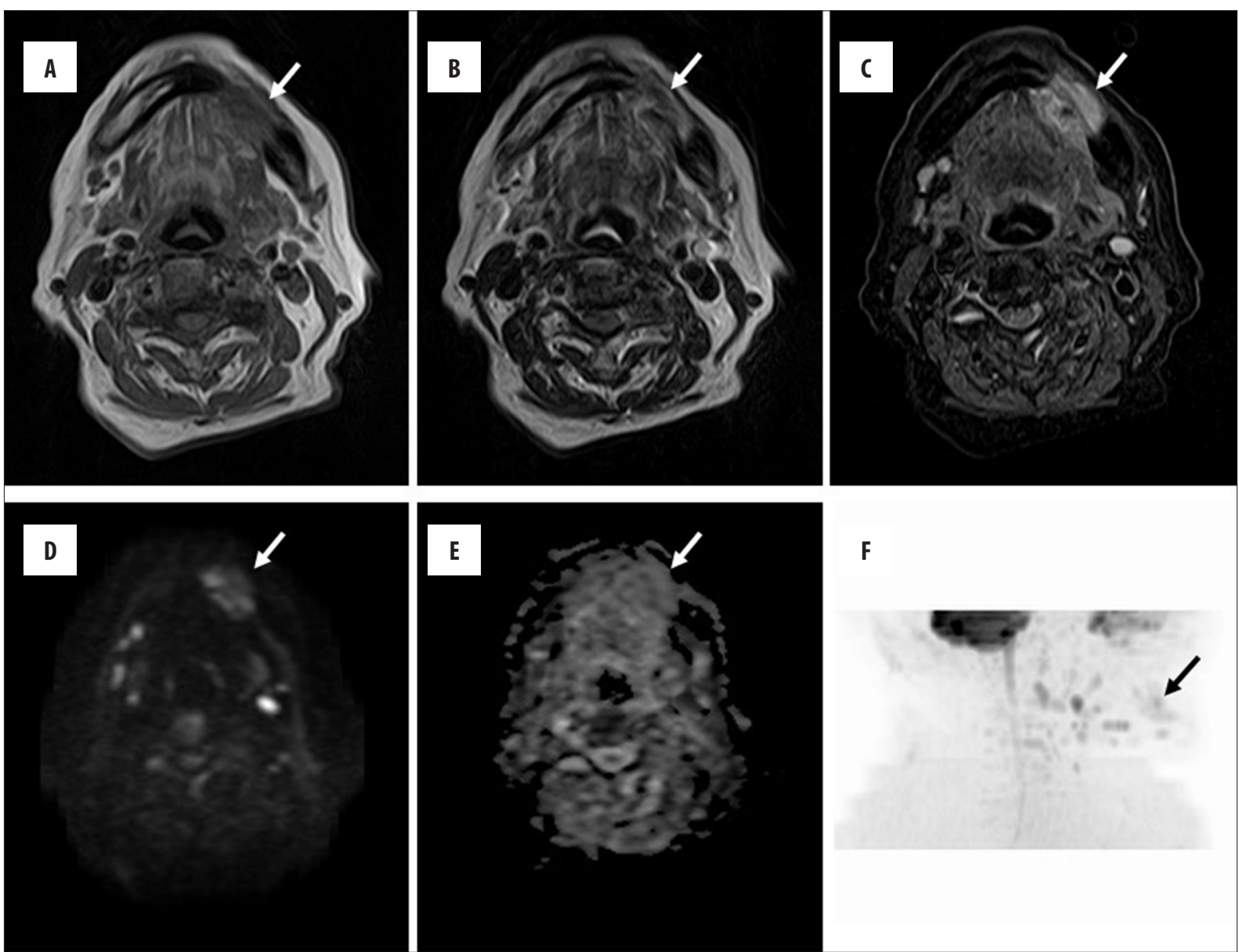

$\mathbf{F}$

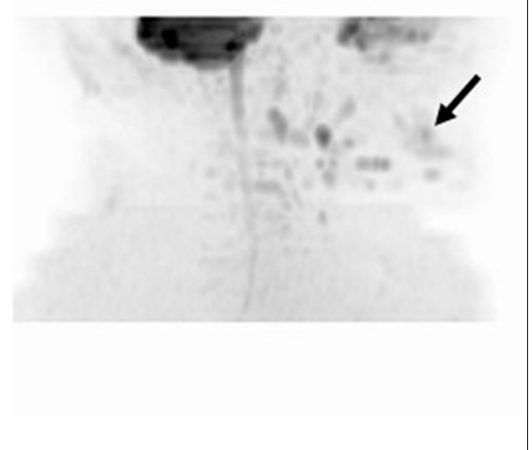

Figure 4. Hemangioma of the left side of the mandible in an 89-year-old female. T1-weighted image shows a low-signal intensity area (arrow) (A). T2-weighted image shows a middle-signal intensity area (arrow) (B). Short TI inversion recovery image shows a high-signal intensity area (arrow) (C). Diffusion-weighted image shows a high-signal intensity area (arrow) (D). Apparent diffusion coefficient map shows a middle-signal intensity area (arrow) (E). Maximum intensity projection (diffusion-weighted image) to shows lesions in an improved way (arrow) (F).

$\left(1.52 \pm 0.31 \times 10^{-3} \mathrm{~mm}^{2} / \mathrm{s}\right)$ was higher than that of odontogenic infections $\left(0.85 \pm 0.36 \times 10^{-3} \mathrm{~mm}^{2} / \mathrm{s}, \mathrm{P}=0.034\right)$ and SCC $\left(1.38 \pm 0.22 \times 10^{-3} \mathrm{~mm}^{2} / \mathrm{s}, \mathrm{P}=0.840\right)$. Driessen et al. [2] indicated that DWI consistently showed both high accuracy and high negative predictive value in squamous cell carcinomas of the head and neck region. We consider that the different ADC values of lesions are linked to the histopathological differences between benign and malignant lesions.

There were several limitations of this study. The sample was relatively small. Moreover, several types of cysts and tumors can occur in the oral and maxillofacial region. Therefore, further research is necessary to validate these results.

\section{Conclusions}

This study aimed to investigate DWI in the oral and maxillofacial region, with a special focus on the usefulness of ADC maps and MIP for characterization of normal structures and lesions. In conclusion, DWI, ADC maps, and MIP can be used to characterize and differentiate normal structures and lesions in the oral and maxillofacial region.

\section{Acknowledgement}

The authors wish to thank radiological technologist T. Miyata, Toshiba Medical Systems and Professor M. Tsuchimochi, Department of Oral and Maxillofacial Radiology, The Nippon Dental University School of Life Dentistry at Niigata.

\section{Conflict of interest}

The authors declare that there are no actual or potential conflicts of interest in relation to this article. 


\section{References:}

1. Serifoglu I, Oz II, Damar M et al: Diffusion-weighted imaging in the head and neck region: Usefulness of apparent diffusion coefficient values for characterization of lesions. Diagn Interv Radiol, 2015; 21: 208-14

2. Driessen JP, van Kempen PM, van der Heijden GJ et al: Diffusionweighted imaging in head and neck squamous cell carcinomas: a systematic review. Head Neck, 2015; 37: 440-48

3. Sakamoto J, Sasaki Y, Otonari-Yamamoto M et al: Comparison of various methods for quantification of apparent diffusion coefficient of head and neck lesions with HASTE diffusion-weighted MR imaging. Oral Surg Oral Med Oral Pathol Oral Radiol, 2012; 114: 266-76

4. Ryoo I, Kim JH, Choi SH et al: Squamous cell carcinoma of the head and neck: comparison of diffusion-weighted MRI at b-values of 1,000 and $2,000 \mathrm{~s} / \mathrm{mm}^{2}$ to predict response to induction chemotherapy. Magn Reson Med Sci, 2015; 14: 337-45

5. Li S, Cheng J, Zhang Y et al: Differentiation of benign and malignant lesions of the tongue by using diffusion-weighted MRI at 3.0T. Dentomaxillofac Radiol, 2015; 44: 20140325

6. Sakamoto J, Yoshino N, Okochi $\mathrm{K}$ et al: Tissue characterization of head and neck lesions using diffusion-weighted MR imaging with SPLICE. Eur J Radiol, 2009; 69: 260-68

7. Abdel Razek AA, Gaballa G, Elhawarey G et al: Characterization of pediatric head and neck masses with diffusion-weighted MR imaging. Eur Radiol, 2009; 19: 201-8
8. Schakel T, Hoogduin JM, Terhaard CH et al: Diffusion weighted MRI in head-and-neck cancer: geometrical accuracy. Radiother Oncol, 2013; 109: 394-97

9. Kito S, Morimoto $\mathrm{Y}$, Tanaka T et al: Utility of diffusion-weighted images using fast asymmetric spin-echo sequences for detection of abscess formation in the head and neck region. Oral Surg Oral Med Oral Pathol Oral Radiol Endod, 2006; 101: 231-38

10. Helenius J, Soinne L, Perkio J et al: Diffusion-weighted MR imaging in normal human brains in various age groups. Am J Neuroradiol, 2002; 23: 194-99

11. Guo AC, Provenzale JM, Cruz LC Jr. et al: Cerebral abscesses: investigation using apparent diffusion coefficient maps. Neuroradiology, 2001; 43: 370-74

12. Srinivasan $A$, Dvorak $R$, Perni $K$ et al: Differentiation of benign and malignant pathology in the head and neck using 3T apparent diffusion coefficient values: Early experience. Am J Neuroradiol, 2008; 29: 40-44

13. Abdel Razek AA, Gaballa G, Elhawarey G et al: Characterization of pediatric head and neck masses with diffusion-weighted MR imaging. Eur Radiol, 2009; 19: 201-8

14. Maeda M, Kato H, Sakuma $\mathrm{H}$ et al: Usefulness of the apparent diffusion coefficient in line scan diffusion-weighted imaging for distinguishing between squamous cell carcinomas and malignant lymphomas of the head and neck. Am J Neuroradiol, 2005; 26: $1186-92$ 